\title{
What's in a Name?: Providing Clarity in the Definition of Minimally Invasive Parathyroidectomy
}

\author{
Sendhil Rajan ${ }^{1}$ (D) Gaurav Agarwal ${ }^{1}$
}

Published online: 7 July 2015

(C) Société Internationale de Chirurgie 2015

To the Editor,

The study "What's in a Name?: Providing Clarity in the Definition of Minimally Invasive Parathyroidectomy" (MIP) authored by James et al. [1] published in the April 2015 issue of World Journal of Surgery is a laudable effort. This review has aimed to extinguish the ever increasing ambiguity of the term "MIP" that has confused surgeons, physicians, and patients alike. We commend the authors for the idea of an alternative definition to replace this confusing surgical terminology. Here we share a few views of our own regarding the same.

When defining the surgical procedure performed, the authors have described 'Operative Approach' to convey information regarding whether the surgical procedure was open (including incision size), endoscopic, video-assisted or robotic. We feel that this does not address the issue comprehensively. In open "MIP", incision site may vary: most surgeons use a lateral incision, while some may use a small centrally placed incision. Also, endoscopic and robotic parathyroidectomy have now become terms that encompass a heterogeneous group of procedures. These may peruse a cervical/axillary/breast/chest wall/hybrid approach for neck, as also the thoracoscopic approach for removal of mediastinal tumors. Further, such operations may use pneumo-insufflation or be gas-less procedures [2].

Gaurav Agarwal

gaurav@sgpgi.ac.in; gauravbsi@gmail.com

Sendhil Rajan

sendhil1986@gmail.com

1 Department of Endocrine \& Breast Surgery, Sanjay Gandhi Postgraduate Institute of Medical Sciences (SGPGIMS), Rae Bareilly Road, Lucknow, Uttar Pradesh 226014, India

It would be worthwhile to include these details in the defining criteria for a more accurate description of the procedure. This would have a bearing on the patient/physician perception of the surgical procedure performed.

Another aspect of parathyroid surgery that is prone to create confusion is the location of the adenoma which has been removed. Imaging results often predict an inferior parathyroid adenoma which during surgery, turns out to be a descended superior adenoma. Some have therefore stressed on knowing if the adenoma is ventral or dorsal, rather than superior or inferior. A wide variety of entopic and ectopic locations of the adenoma are possible and should be documented accurately to help a possible future intervention in case of persistent or recurrent disease. A solution to this problem may be using the system proposed by Perrier et al. [3] to classify the glands using the letters A-G to describe exact gland locations, which has since been validated [4].

\section{References}

1. James BC, Kaplan EL, Grogan RH, Angelos P (2015) What's in a name?: providing clarity in the definition of minimally invasive parathyroidectomy. World J Surg 39(4):975-980. doi:10.1007/ s00268-014-2902-7

2. Taskin HE, Arslan NC, Aliyev S, Berber E (2013) Robotic endocrine surgery: state of the art. World J Surg 37(12):2731-2739. doi:10.1007/s00268-013-2154-y

3. Perrier ND, Edeiken B, Nunez R, Gayed I, Jimenez C, Busaidy N, Potylchansky E, Kee S, Vu T (2009) A novel nomenclature to classify parathyroid adenomas. World J Surg 33(3):412-416. doi:10.1007/s00268-008-9894-0

4. Mazeh H, Stoll SJ, Robbins JB, Sippel RS, Chen H (2012) Validation of the "Perrier" parathyroid adenoma location nomenclature. World J Surg 36(3):612-616. doi:10.1007/s00268-011$1412-0$ 